\title{
Kinetic, Mechanistic and Spectrophotometric Study of Micelle Effects on the Oxidation of Thiourea by Quinolinium Dichromate in Perchloric Acid Medium
}

\author{
D. SURYA KALA ${ }^{\mathrm{a}, *}$, ASIF $^{\mathrm{a}}$ K. RAMA KRISHNA ${ }^{\mathrm{a}}$ \\ M.K.CHAKRAVARTHY ${ }^{\mathrm{b}}$ and P.V. SUBBA RAO ${ }^{\mathrm{c}}$
}

${ }^{\text {a } D e p a r t m e n t ~ o f ~ C h e m i s t r y, ~ I n s t i t u t e ~ o f ~ S c i e n c e, ~ G I T A M ~ U n i v e r s i t y, ~ V i s a k h a p a t n a m, ~ I n d i a ~}$

${ }^{\mathrm{b}}$ Department of Chemistry, ANITS Engineering College, Visakhapatnam, India

${ }^{\mathrm{c}}$ Department of Chemistry, Gayatri Vidya Parishad, Visakhapatnam, India

dsuryakala@yahoo.co.in

Received 20 February 2013 / Accepted 19 March 2013

\begin{abstract}
The kinetic investigation of oxidation of thiourea by quinolinium dichromate (QDC) in perchloric acid medium at constant ionic strength was studied spectrophotometrically at $440 \mathrm{~nm}$. A stoichiometric ratio of 3:1 with thiourea versus QDC was observed. The reaction was first order with respect to thiourea, monomeric QDC (QMC) and $\mathrm{HClO}_{4}$. Induced polymerization of acrylonitrile was observed. The mechanism involved the attack of protonated monomeric QDC (QMC) on the substrate in the rate determining step forming the products. Addition of $\mathrm{Mn}(\mathrm{II})$ has no effect on the reaction rate. The effect of anionic micelle (SDS) and neutral micelle (TX-100) on the system was studied using Berezin's kinetic model and observed a partial inhibitory effect on the rate of the reaction. The thermodynamic parameters like $\Delta \mathrm{E}_{\mathrm{a}} \Delta \mathrm{S}$ and $\Delta \mathrm{G}$ have been calculated and possible mechanism was proposed.
\end{abstract}

Keywords: Monomeric quinolinium dichromate, QMC, Oxidation, Effect of anionic and neutral (TX100) micelle

\section{Introduction}

Thiourea containing sulfur and nitrogen atoms is susceptible to oxidation by a large number of oxidants giving rise to various products including urea, sulfides, oxides of sulfur and nitrogen. Reactions of chromium(VI) with sulphur containing ligands have been the subject of several recent studies ${ }^{1-4}$. Earlier work on the oxidation of thiourea by dichromate refers to its oxidation to formamidine disulphide in which Singh et $a l^{5}$ have claimed quantitative results. In the reaction with chromium(VI) evidence has been provided by Mc.Auley et al. ${ }^{6}$ for an inner-sphere route with the formation of a sulphur-bonded chromate ester. The redox reaction between vanadium $(\mathrm{V})$ and thiourea has been investigated at $25{ }^{0} \mathrm{C}$ over the hydrogen ion concentration range $\left[\mathrm{H}^{+}\right]=0.2-1.40 \mathrm{~mol} \mathrm{dm}{ }^{-3}$ where both one and two electron transfer pathways are proposed and similarities in the reaction scheme with that of the corresponding $\mathrm{Cr}(\mathrm{VI})$ reactions are discussed by Zamid Amjad et al. ${ }^{7}$. 
The oxidation reactions of $N$-acetyl thiourea (ACTU) by chlorite and chlorine dioxide were studied ${ }^{8}$ in acidic media where the stoichiometry of the reaction is $2: 1$. Similar reactions of the oxidation of thiourea by bromate in acidic solution was studied by Simoyi et al. ${ }^{9}$ and found that the mechanism requires the cleavage of the $\mathrm{X}-\mathrm{C}$ bond to form urea and $\mathrm{SO}_{4}{ }^{2-}$. The oxidation of thiourea by iodate, a new type of oligo oscillatory reaction was studied ${ }^{10}$ where the end products are sulphate ions, ammonium ions and carbon dioxide. Kinetics of the chromium(VI) by thiourea reaction in the presence of polyacrylamide was reported by Southard et al. ${ }^{11}$.

Kinetic study of the reduction of chromium(VI) by thiourea ${ }^{12}$ in the absence and presence of manganese(II), cerium(IV) and EDTA have been studied and the reaction follows overall third order kinetics, first order each in $\mathrm{Cr}(\mathrm{VI})$, thiourea and $\mathrm{HClO}_{4}$. The reaction involves the formation of chromium(VI)-thiourea complex which decomposes to the products and $\mathrm{Cr}(\mathrm{III})$. Reports from Arifoglu et al. ${ }^{13}$ reveals that reactions of thiourea with hydrogen peroxide under certain conditions produce a powerful reductive bleaching agent, which is used in the textile industry ${ }^{13,14}$. Ayres observed that thiourea and its derivatives are used as corrosion inhibitors ${ }^{15}$ in industrial equipment such as boilers, which develop scales due to corrosion. The author has taken up the kinetic study of micellar effects on the oxidation of thiourea by a complexed chromium(VI) reagent, quinolinium dichromate (QDC) i.e. $\left(\mathrm{C}_{9} \mathrm{H}_{7} \mathrm{~N}^{+} \mathrm{H}\right)_{2} \mathrm{Cr}_{2} \mathrm{O}_{7}{ }^{2-}$ in acid medium is a mild oxidizing agent to find out any mechanistic and kinetic differences compared to the oxidation by aqueous chromium(VI).

\section{Experimental}

All the chemicals were of high grade quality and were used as received without further purification. Quinolinium dichromate (QDC) was prepared by the reported method ${ }^{16}$ and standardized $^{17}$. Its purity was checked by spectral analysis. The infrared spectrum $(\mathrm{KBr})$ exhibited bands at $930,875,765$ and $730 \mathrm{~cm}^{-1}$, characteristic of the dichromate ion. $0.1 \mathrm{Mol}$ $\mathrm{dm}^{-3}$ solution of thiourea (TU) was prepared and standardized idometrically ${ }^{18}$. A fluka sample of sodium dodecyl sulphate (SDS) has been used in the preparation of $0.1 \mathrm{~mol} \mathrm{dm}^{-3}$ solution and it's purity was tested by determining the $\mathrm{CMC}^{19}$ conductometrically and has been reported ${ }^{20,21}$ to be $1.0 \times 10^{-3} \mathrm{~mol} \mathrm{dm}^{-3}$. Triton X-100 (TX-100) (Fluka) was cleared of any lowboiling impurities by exposure to vaccum for $3 \mathrm{~h}$ at $70{ }^{\circ} \mathrm{C}$ following the procedure given by Kumar and Balasubrahmanium ${ }^{22}$. The CMC of TX-100 has been reported ${ }^{23}$ as $2.4 \times 10^{-4} \mathrm{~mol} \mathrm{dm}^{-3}$. Sodium perchlorate (Fluka) and perchloric acid were used without purification and enabled variation of hydrogen ion concentration at a constant ionic strength $(1.0 \mathrm{M})$. Acrylonitrile was washed with $1 \mathrm{~N} \mathrm{NaOH}$ and then with water. It is dried over anhydrous $\mathrm{CaCl}_{2}$ and finally distilled. The fraction between $77-79{ }^{\circ} \mathrm{C}$ was collected and immediately used.

\section{Kinetic measurements}

The reaction was followed by measuring the optical density of the unreacted QDC at $440 \mathrm{~nm}$ using Perkin Elmer Lamda $25 \mathrm{UV} / \mathrm{V}$ is spectrophotometer. The experiments were carried out in a temperature controlled $\left( \pm 0.1^{0} \mathrm{C}\right)$ water bath. The reaction was initiated by injecting, QDC $\left(2.0 \times 10^{-3} \mathrm{~mol} \mathrm{dm}^{-3}\right)$ into the thiourea $\left(2.0 \times 10^{-2} \mathrm{~mol} \mathrm{dm}^{-3}\right)$ and perchloric acid $\left(0.01 \mathrm{~mol} \mathrm{dm}^{-3}\right)$ mixture. The reaction was monitored by determining the absorbance at different times and $\log$ (absorbance) vs. time plots are perfectly linear for at least $95 \%$ of the reaction. The reactant concentrations have been chosen such that Beer's law is strictly obeyed. The pseudo first order constants determined in duplicate agreed within $\pm 5 \%$. 


\section{Stoichiometry}

To determine the stoichiometry of the reaction a known concentration of thiourea was mixed with different concentrations of QDC at $\left[\mathrm{H}^{+}\right]=0.01 \mathrm{~mol} \mathrm{dm}^{-3}$ in water. The reactions were kept overnight for the completion of the reaction and the absorbance was measured at $440 \mathrm{~nm}$. It was found that three moles of thiourea requires one mole of QDC (Scheme 1).

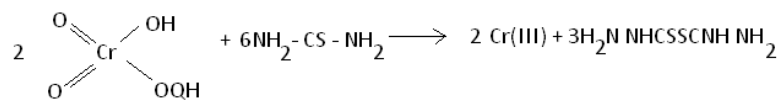

\section{Product analysis}

\section{Scheme 1}

In order to confirm the products $150 \mathrm{mg}$ of a stoichiometric excess of QDC $\left(0.1 \mathrm{~mol} \mathrm{dm}^{-3}\right)$ in water was added slowly to a cooled acidic solution containing thiourea. The solution rapidly turned green and four volumes of ethanol were added followed by concentrated $\mathrm{HCl}$ $\left(50 \mathrm{~cm}^{3}\right)$. On cooling, crystals of $\mathrm{CC}^{1}$-dithiobis (formamidinium) ${ }^{24}$ were obtained identical to those prepared by $\mathrm{H}_{2} \mathrm{O}_{2}$ oxidation ${ }^{25}$. Further confirmation of this disulphide as a product was given by the ready decomposition to sulphur in acid media.

\section{Results and Discussion}

\section{Effect of variation of [QDC]}

Under the conditions, [TU] $\gg[Q D C]$ and at fixed concentrations of thiourea, perchloric acid, ionic strength the plots of $\log$ (absorbance) versus time were found to be linear for at least $95 \%$ reaction showing that the reaction obeys first order kinetics with respect to QDC (Table 1). The pseudo first order rate constants, $\mathrm{k}_{1}$, determined at different [QDC] ranging from $1.0 \times 10^{-3}$ mol dm $\mathrm{dm}^{-3}$ to $3.0 \times 10^{-3} \mathrm{~mol} \mathrm{dm}{ }^{-3}$ was constant. The pseudo first order rate constant $\mathrm{k}_{1}$ under the conditions $[\mathrm{QDC}]<[\mathrm{TU}]$ does not change with change in the concentration of [QDC], showing that QDC is present in the monomeric form predominantly i.e., quinilinium monochromate $(\mathrm{QMC})$ or else change in $\mathrm{k}_{1}$ should have been observed due to expectedly different reactivity of dimeric QDC whose content increases with increasing [QDC].

\section{Effect of varying [thiourea]}

The kinetic runs were carried out by keeping $[\mathrm{TU}]>>[\mathrm{QDC}]$ at different concentration of thiourea in the range of $1.0 \times 10^{-2} \mathrm{~mol} \mathrm{dm}^{-3}$ to $8.0 \times 10^{-2} \mathrm{~mol} \mathrm{dm}^{-3}$ and fixed concentrations of QDC, acid and other parameters. The pseudo first order rate constants were measured and the plot of $\mathrm{k}_{1}$ versus [TU] (Table 1) which is linear initially shows a limiting behavior at higher thiourea concentration. Further the plot of $1 / \mathrm{k}_{1}$ versus $1 /$ [TU] is a good straight line (Figure 1) with a positive intercept. This is generally observed when an intermediate with appreciable formation constant is formed, which subsequently decomposes to the products.

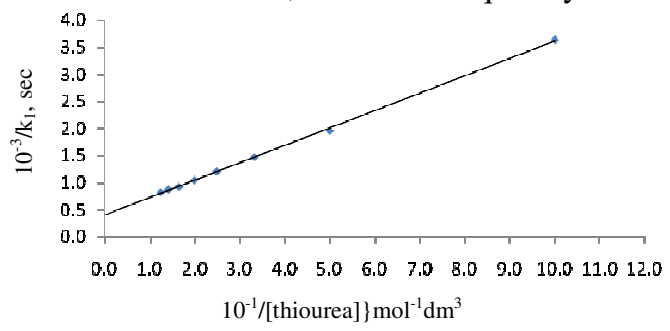

Figure 1. Plot of $1 /\left[\right.$ thiourea] $v s .1 / \mathrm{k}_{1}$ at $[\mathrm{QDC}]=2.0 \times 10^{-3} \mathrm{~mol} \mathrm{dm}^{-3},\left[\mathrm{HClO}_{4}\right]=4.0 \times 10^{-2}$ $\mathrm{mol} \mathrm{dm}{ }^{-3}, \mu=0.25 \mathrm{~mol} \mathrm{dm}^{-3} ; \mathrm{Temp}=30{ }^{\circ} \mathrm{C} \pm 0.1{ }^{\circ} \mathrm{C}$ 


\section{Effect of varying $\left[\mathrm{H}^{+}\right]$}

To study the effect of variation of $\left[\mathrm{H}^{+}\right]$on the reaction rate, $\mathrm{k}_{1}$, was determined at different $\mathrm{H}^{+}$ion concentrations in the range of $1.0 \times 10^{-2} \mathrm{~mol} \mathrm{dm}$ to $10.0 \times 10^{-2} \mathrm{~mol} \mathrm{dm}^{-3}$, at constant ionic strength, QDC, TU and temperature (Table 1). Plot of $\mathrm{k}_{1}$ versus $\left[\mathrm{H}^{+}\right]$is a straight line passing through the origin (Figure 2) confirming the first order behavior with respect to acid. It was observed that there is no $\mathrm{H}^{+}$ion independent path and also lack of any quadratic dependence of rate on $\left[\mathrm{H}^{+}\right]$. The $\mathrm{pK}_{\mathrm{a}}$ of the conjugate base of thiourea has a value in the range -1.20 to $-1.90^{6}$ and hence thiourea cannot be expected to be protonated in the range of $\left[\mathrm{H}^{+}\right]$employed and hence exists in the unprotonated form $\left(\mathrm{NH}_{2}\right)_{2} \mathrm{CS}$.

Table 1. Effect of variation of $[\mathrm{TU}],[\mathrm{QDC}],\left[\mathrm{H}^{+}\right]$on the oxidation kinetics of thiourea by quinolinium dichromate at $303 \mathrm{~K}$ and $\mathrm{I}=0.25 \mathrm{~mol} \mathrm{dm}^{-3}$

\begin{tabular}{|c|c|c|c|}
\hline $10^{2}[\mathrm{TU}] \mathrm{mol} \mathrm{dm}^{-3}$ & $10^{3}[\mathrm{QDC}] \mathrm{mol} \mathrm{dm}^{-3}$ & $10^{2}\left[\mathrm{H}^{+}\right] \mathrm{mol} \mathrm{dm}^{-3}$ & $10^{4} \mathrm{k}_{1} \mathrm{~s}^{-1}$ \\
\hline 2.0 & 1.0 & 2.0 & $2.26 \pm 0.10$ \\
\hline 2.0 & 1.5 & 2.0 & $2.03 \pm 0.11$ \\
\hline 2.0 & 2.0 & 2.0 & $2.13 \pm 0.12$ \\
\hline 2.0 & 2.5 & 2.0 & $2.15 \pm 0.11$ \\
\hline 2.0 & 3.0 & 2.0 & $2.18 \pm 0.10$ \\
\hline 1.0 & 2.0 & 4.0 & $2.76 \pm 0.12$ \\
\hline 2.0 & 2.0 & 4.0 & $5.12 \pm 0.12$ \\
\hline 3.0 & 2.0 & 4.0 & $6.82 \pm 0.11$ \\
\hline 4.0 & 2.0 & 4.0 & $8.31 \pm 0.10$ \\
\hline 5.0 & 2.0 & 4.0 & $9.60 \pm 0.10$ \\
\hline 6.0 & 2.0 & 4.0 & $10.87 \pm 0.12$ \\
\hline 7.0 & 2.0 & 4.0 & $11.51 \pm 0.11$ \\
\hline 8.0 & 2.0 & 4.0 & $12.15 \pm 0.11$ \\
\hline 2.0 & 2.0 & 1.0 & $1.18 \pm 0.10$ \\
\hline 2.0 & 2.0 & 2.0 & $2.19 \pm 0.10$ \\
\hline 2.0 & 2.0 & 4.0 & $4.91 \pm 0.12$ \\
\hline 2.0 & 2.0 & 5.0 & $5.84 \pm 0.11$ \\
\hline 2.0 & 2.0 & 6.0 & $7.42 \pm 0.11$ \\
\hline 2.0 & 2.0 & 8.0 & $9.69 \pm 0.12$ \\
\hline 2.0 & 2.0 & 10.0 & $11.20 \pm 0.10$ \\
\hline \multicolumn{4}{|c|}{$14.0-$} \\
\hline \multicolumn{4}{|c|}{12.0} \\
\hline \multicolumn{4}{|c|}{10.0} \\
\hline \multicolumn{4}{|c|}{880} \\
\hline \multicolumn{4}{|l|}{$\begin{array}{cc}-\overrightarrow{0} & \\
\stackrel{-}{0} & 6 .\end{array}$} \\
\hline \multicolumn{4}{|c|}{${ }_{4.0}$} \\
\hline \multicolumn{4}{|c|}{2.0} \\
\hline \multicolumn{4}{|c|}{$8.05 .0: 0.011 .012 .0$} \\
\hline
\end{tabular}

Figure 2. Plot of $\left[\mathrm{H}^{+}\right]$vs. $\mathrm{k}_{1}$ at $[\mathrm{QDC}]=2.0 \times 10^{-3} \mathrm{~mol} \mathrm{dm}^{-3} ;[\mathrm{TU}]=2.0 \times 10^{-2} \mathrm{~mol} \mathrm{dm}$; $\mu=0.25 \mathrm{~mol} \mathrm{dm}{ }^{-3}$; Temp $=30{ }^{0} \mathrm{C} \pm 0.1{ }^{\circ} \mathrm{C}$ 


\section{Effect of varying ionic strength}

Ionic strength of the medium using $\mathrm{NaClO}_{4}$ was varied in the range $(0.17-0.79) \mathrm{mol} \mathrm{dm}{ }^{-3}$, keeping all other parameters constant. The pseudo first order rate constants were observed to be independent of reaction rate. It was observed that ionic strength has no influence on the reaction rate.

\section{SDS effect and TX-100 effect}

To investigate the micellar effects of SDS (anionic surfactant) and TX -100 (neutral surfactant) on rate, runs were carried out at different initial concentrations of SDS, TX-100 respectively keeping [QDC] $[\mathrm{TU}],\left[\mathrm{H}^{+}\right]$. The ionic strength was maintained constant at each kinetic run by adding sodium perchlorate which has been found to have no effect on the rate of reaction. The pseudo first order rate constants were obtained from log absorbance vs. time graphs at $440 \mathrm{~nm}$ (Figure $3 \& 4$ ). The results show that there is small decelerating effect of [SDS] and [TX-100] on the reaction rate. The reaction is inhibited both by Triton $\mathrm{X}$ and SDS micells. This can be explained as due to lack of its interaction of thiourea with the micells though they interact with QMC. Thus the reaction takes place only in the aqueous pseudo phase and as the micellar concentration increases more and more QMC is removed from this phase and bound by the micelle. This results in the decrease in the concentration of $\mathrm{QMC}$ in aqueous phase thus explaining the inhibitory effect of the micelles on the reaction.

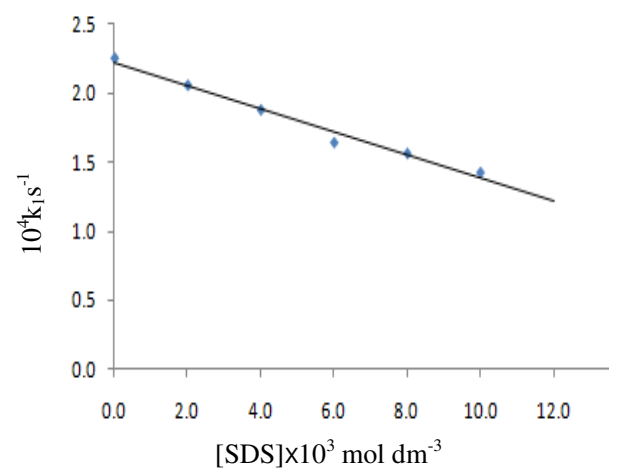

Figure 3. Plot of [SDS] vs. $\mathrm{k}_{1}$

$\left(\right.$ At $[Q D C]=2.0 \times 10^{-3} \mathrm{~mol} \mathrm{dm^{-3 }} ;[T . U]=2.0 \times 10^{-2}$ mol dm$\left.m^{-3} ; \mathrm{HClO}_{4}\right]=2.0 \times 10^{-2} \mathrm{~mol} \mathrm{dm^{-3 }} ; \mu=0.25$ mol dm ${ }^{-3}$; Temp $=30^{\circ} \mathrm{C} \pm 0.1^{\circ} \mathrm{C}$ )

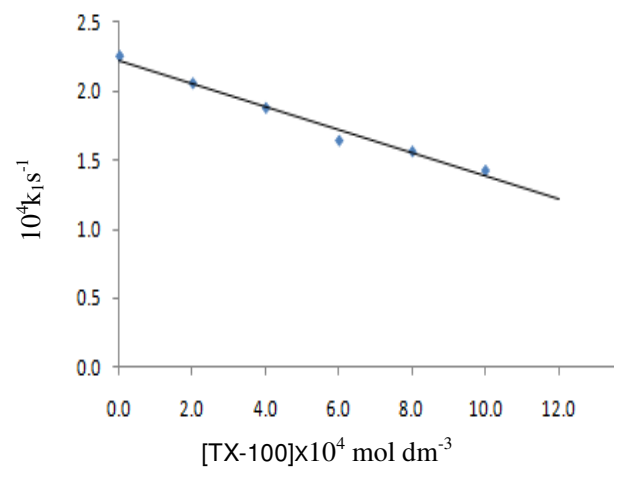

Figure 4. Plot of [TX-100] vs. $\mathrm{k}_{1}$ (At $[Q D C]=2.0 \times 10^{-3} \mathrm{~mol} \mathrm{dm^{-3 }} ; \quad[T . U]=$ $2.0 \times 10^{-2} \mathrm{~mol} \mathrm{dm}^{-3} ;\left[\mathrm{HClO}_{4}\right]=2.0 \times 10^{-2} \mathrm{~mol}$ $\mathrm{dm}^{-3} ; \mu=0.25 \mathrm{~mol} \mathrm{dm} \mathrm{m}^{-3} ; \mathrm{Temp}=30^{\circ} \mathrm{C} \pm 0.1{ }^{\circ} \mathrm{C}$

\section{Effect of $M n(I I)$ concentration on rate}

Kinetic runs were carried in the presence of manganese(II), by varying its concentration in the range of $2.0 \times 10^{-4} \mathrm{~mol} \mathrm{dm}^{-3}$ to $1.0 \times 10^{-2} \mathrm{~mol} \mathrm{dm}^{-3}$ and the addition of manganese(II) which is known to be a trap for $\mathrm{Cr}(\mathrm{IV})$, did not have any effect on the rate of oxidation of thiourea by QDC in perchloric acid medium.

\section{Initiation of vinyl polymerisation}

$1.5 \mathrm{~mL}$ of $0.01 \mathrm{~mol} \mathrm{dm}^{-3}$ thiourea, $3.0 \mathrm{~mL}$ of $0.05 \mathrm{~mol} \mathrm{dm}^{-3} \mathrm{QDC}$ and $0.5 \mathrm{~mL}$ of $1.0 \mathrm{~mol} \mathrm{dm} \mathrm{dm}^{-3}$ perchloric acid were kept in the lower limb of a Thunberg tube. In the upper limb $2 \mathrm{~mL}$ of acrylonotrile were placed. The tube was closed and the air inside the tube was removed by using vacuum pump. Then both the solutions were mixed by shaking the tube. Formation of polymerization was observed. However, a mixture of QDC, acid under these experimental conditions was not found to initiate vinyl polymerization during the time taken for the formation of polymer in the presence of the substrate. The result indicates that the reaction proceed through the formation of a free radical mechanism. 


\section{Activation parameters}

The values of $\mathrm{k}_{1}$ were determined at three different temperatures and presented in table (Table 2). The analysis of temperature effect was not attempted because $\mathrm{k}_{1}$ being overall pseudo first order rate constant, involves the equilibrium constant, $\mathrm{K}_{\mathrm{a}}$. However, the apparent activation energy from these data has been obtained by using the equation

$$
\ln \frac{k_{1}\left(T_{2}\right)}{k_{1}\left(T_{1}\right)}=\frac{E_{a}}{R}\left[\frac{1}{T_{1}}-\frac{1}{T_{2}}\right]
$$

Table 2. $[\mathrm{QDC}]=2.0 \times 10^{-3} \mathrm{~mol} \mathrm{dm}^{-3} ;[\mathrm{TU}]=2.0 \times 10^{-2} \mathrm{~mol} \mathrm{dm}^{-3} ;\left[\mathrm{HClO}_{4}\right]=4.0 \times 10^{-2} \mathrm{~mol} \mathrm{dm}^{-3}$; $\mu=0.25 \mathrm{~mol} \mathrm{dm}{ }^{-3} \mathrm{E}_{\mathrm{a}}=17 \mathrm{~kJ} / \mathrm{mol}, \Delta \mathrm{H}=14 \mathrm{~kJ} / \mathrm{mol}, \Delta \mathrm{S}=-300 \mathrm{~J} \mathrm{~K}^{-1} \mathrm{~mol}^{-1}, \Delta \mathrm{G}=111 \mathrm{~kJ} / \mathrm{mol}$

\section{Mechanism}

\begin{tabular}{cc}
\hline Temperature, $\pm 0.1 \mathrm{~K}$ & $10^{4} \mathrm{k}_{1} \mathrm{~s}^{-1}$ \\
\hline 303 & $4.80 \pm 0.14$ \\
313 & $8.72 \pm 0.14$ \\
323 & $17.27 \pm 0.13$ \\
\hline
\end{tabular}

A plot of $1 / \mathrm{k}_{1}$ versus $1 /[\mathrm{TU}]$ is linear with a positive intercept resembling Michailies type of kinetics. This type of rate dependence on thiourea concentration indicates that the reaction mechanism involves the formation of 1:1 complex between QMC species and thiourea and rate determining decomposition of this 1:1 complex. Quinoline added to the reaction mixture of the QDC and the substrate has no effect on the rate of the reaction and this rules out the presence of the pre equilibrium before the rate determining step in the mechanism, and the oxidant reacts only in the form of $\mathrm{QMC}, \mathrm{QH}^{+} \mathrm{HCrO}_{4}{ }^{-}$after protonation.

Interestingly, this kinetic pattern is different from the one observed in the oxidation of thiourea by aqueous $\mathrm{Cr}(\mathrm{VI})$. In this case Mc-Auley et al. ${ }^{6}$ reported that the mechanism involves another rate determining step involving intermediate complex $(\mathrm{X})$ and thiourea $(\mathrm{L})$, producing $\mathrm{Cr}(\mathrm{IV})$ and the oxidation product of thiourea.

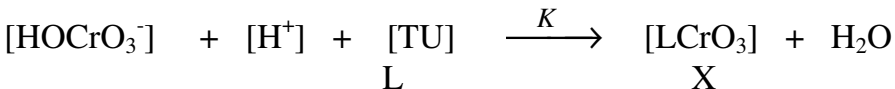

$$
\begin{aligned}
& {\left[\mathrm{O}_{3} \mathrm{CrL}\right] \stackrel{k}{\longrightarrow} \mathrm{Cr}(\mathrm{V})+\mathrm{L}^{\circ}} \\
& {\left[\mathrm{O}_{3} \mathrm{CrL}\right]+\left[\mathrm{H}^{+}\right]+\mathrm{L} \stackrel{k_{1}}{\longrightarrow} \mathrm{Cr}(\mathrm{IV})+\mathrm{L}^{1}-\mathrm{L}^{1}} \\
& {\left[\mathrm{O}_{3} \mathrm{CrL}\right]+2\left[\mathrm{H}^{+}\right]+\mathrm{L} \stackrel{k_{2}}{\longrightarrow} \mathrm{Cr}(\mathrm{IV})+\mathrm{L}^{1}-\mathrm{L}^{1}} \\
& 2 \mathrm{~L} \longrightarrow \mathrm{L}^{1}-\mathrm{L}^{1}
\end{aligned}
$$

This gives the rate-law

$$
\text { Rate }=\frac{-d[C r(V I)}{d t}=\frac{\left\{k_{0}+k_{1}\left[H^{+}\right][L]+k_{2}\left[H^{+}\right]^{2}[L]\right\} K[L]\left[H^{+}\right][Q]_{t}}{\left(1+K[L]\left[H^{+}\right]\right)}
$$

At the concentrations of $\mathrm{H}^{+}$employed by the present author, the rate limiting step involving $\mathrm{O}_{3} \mathrm{CrL}$ and $\mathrm{L}$ is also absent, thus, precluding quadratic dependence of rate on [thiourea]. The author proposes the following mechanism (Scheme 2 and Scheme 3) to explain the observed kinetics.

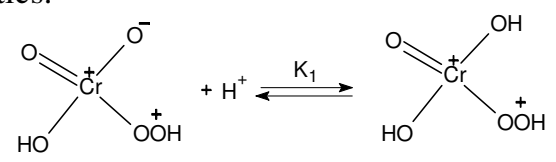




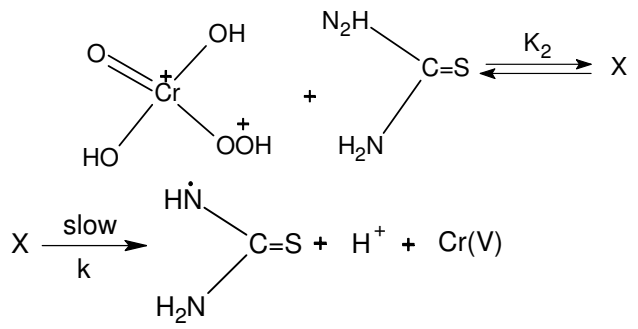

Scheme 2

$$
\begin{aligned}
\mathrm{Cr}(\mathrm{V})+\mathrm{NH}_{2} \mathrm{CS} \mathrm{NH}_{2} \stackrel{\text { fast }}{\longrightarrow} \mathrm{Cr}(\mathrm{IV})+\mathrm{NHCSNH}_{2}{ }^{-}+\mathrm{H}^{+} \\
\mathrm{Cr}(\mathrm{IV})+\mathrm{NH}_{2} \mathrm{CSNH}_{2} \stackrel{\text { fast }}{\longrightarrow} \mathrm{NHCSNH}_{2}+\mathrm{Cr}(\mathrm{III}) \\
2 \mathrm{NHCSNH}_{2} \stackrel{\text { fast }}{\longrightarrow} \mathrm{H}_{2} \mathrm{~N} \mathrm{NHCS} \mathrm{SCNHNH}_{2}
\end{aligned}
$$

Applying the equilibrium technique the following rate law is derived for the Scheme 2. Applying mass balance to QMC

$$
\begin{aligned}
{[\mathrm{HQMC}]_{\mathrm{t}}=[\mathrm{HQMC}]+[\mathrm{X}] } & =\frac{[\mathrm{X}]}{\mathrm{K}_{2}[\mathrm{~T} . \mathrm{U}]}+[\mathrm{X}] \quad=\frac{[\mathrm{X}]+\mathrm{K}_{2}[\mathrm{~T} . \mathrm{U}][\mathrm{X}]}{\mathrm{K}_{2}[\mathrm{~T} . \mathrm{U}]} \\
\therefore[\mathrm{X}] & =\frac{\mathrm{K}_{2}[\mathrm{~T} . \mathrm{U}][\mathrm{HQMC}]_{t}}{1+\mathrm{K}_{2}[\mathrm{~T} . \mathrm{U}]} \\
\text { Rate }=\mathrm{k}[\mathrm{X}] & =\frac{\mathrm{kK}_{2}[\mathrm{~T} . \mathrm{U}][\mathrm{HQMC}]_{\mathrm{t}}}{1+\mathrm{K}_{2}[\mathrm{~T} . \mathrm{U}]} \\
& =\frac{\mathrm{kK}_{1} \mathrm{~K}_{2}[\mathrm{~T} . \mathrm{U}][\mathrm{QMC}]_{\mathrm{t}}\left[\mathrm{H}^{+}\right]}{1+\mathrm{K}_{2}[\mathrm{~T} . \mathrm{U}]} \\
-\frac{d}{d t}[Q M C] & =\frac{k K_{1} K_{2}[Q M C]_{t}[T U]\left[H^{+}\right]}{1+K_{2}[T . U]}
\end{aligned}
$$

The pseudo first order rate constant $\mathrm{k}_{1}$ is given by

$$
\begin{aligned}
k_{1} & =\frac{k K_{1} K_{2}[T U]\left[H^{+}\right]}{1+K_{2}[T \cdot U]} \\
\frac{1}{k_{1}} & =\frac{1}{k K_{1} K_{2}[T U]\left[H^{+}\right]}+\frac{1}{k K_{1}\left[H^{+}\right]}
\end{aligned}
$$

According to equation 15 , a plot of $1 / \mathrm{k}_{1}$ versus $1 /[\mathrm{T} . \mathrm{U}]$ is linear with a positive intercept and

$$
\text { slope }=\frac{1}{k K_{1} K_{2}\left[H^{+}\right]} \text {and intercept }=\frac{1}{k K_{1}\left[H^{+}\right]}
$$

From the values of slope and intercept $\mathrm{K}_{2}$ has been found to be $12.5 \mathrm{~mol} \mathrm{dm}{ }^{-3}$. This value of $\mathrm{K}_{2}$ is much smaller than the one reported $\left(282 \mathrm{~mol} \mathrm{dm}^{-3}\right.$ at $\left.30{ }^{\circ} \mathrm{C}\right)$ by Mc-Auley et al. ${ }^{6}$ for the 1:1 complex monomer $\mathrm{HCrO}_{4}^{-}$and thiourea.This explains lower rate of QDC oxidation compared to oxidation by aqueous $\mathrm{Cr}(\mathrm{VI})$. If a two electron rate determining step is envisaged, the following scheme (Scheme 3) of mechanism can be written.

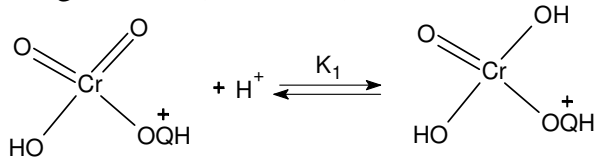




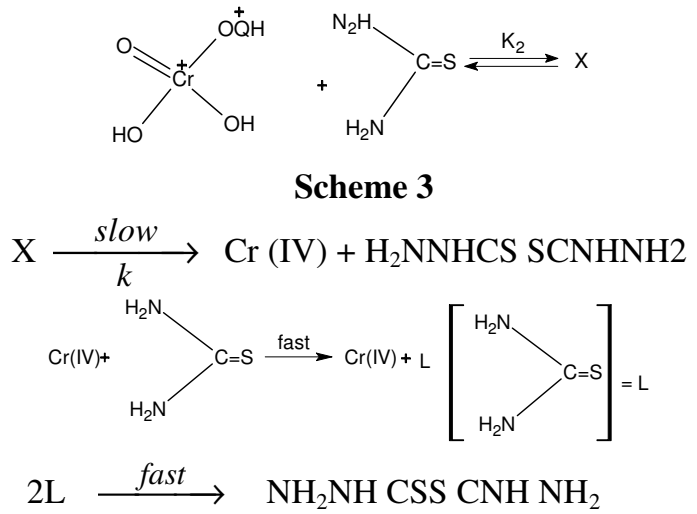

However the observed kinetics cannot distinguish between the two mechanisms. But the observed lack of dependence of rate on added manganese(II) concentration, (( $\mathrm{Mn}$ (II) is known to be a trap for $\mathrm{Cr}(\mathrm{IV})^{6}$ ) points to the greater probability of Scheme 2 (Scheme 2 is also supported by free radical mechanism through the formation of vinyl polymerization) as suggested by Mc-Auley et al. ${ }^{6}$ in the oxidation of thiourea by aqueous chromium(VI). This is also in accordance with rate determining reduction of $\mathrm{Cr}(\mathrm{VI})$ to $\mathrm{Cr}(\mathrm{V})$ rather than $\mathrm{Cr}(\mathrm{IV})$ observed generally for one electron reductants. It has been reported that $\mathrm{Cr}(\mathrm{VI})$ in the rate determining step is reduced to $\mathrm{Cr}(\mathrm{V})$ with one electron oxidants and to $\mathrm{Cr}(\mathrm{IV})$ by two electron oxidants. In the present study sole product of oxidation of thiourea is a disulphide and thus thiourea acts as a one electron reductant in the individual redox stages, producing thiourea free radical which dimerises in fast step to give a disulphide product.

\section{Conclusion}

The kinetic data and the products obtained in the present investigation demonstrated that the mechanistic path way for the oxidation of thiourea by QDC proceeds via free radical mechanism and the active species is the monomeric QDC (QMC) in the protonated form $\left\{\mathrm{Q} \mathrm{H}^{+} \mathrm{H}_{2} \mathrm{CrO}_{4}\right\}$ in the rate determining step. The effect of micelle on the oxidation reaction can be emphasized. A possible mechanism and a related rate law have been worked out. In the conclusion it can be said that role of chromium(VI) is well identified in quinolinium dichromate.

\section{References}

1. Baldea I and Niac G, Inorg Chem., 1968, 7, 1232-1234.

2. Edmonds M I, Howlett K E and Wedzicha B L, J Chem Soc (A), 1970, 2866-2870.

3. Muirhead K A, Haight G P Jr and Beattie J K, J Am Chem Soc., 1972, 94, 3006-3010.

$4 \quad$ Muirhead K A and Haight G P Jr, Inorg Chem., 1973, 12, 1116-1120.

5. Singh B and Verma B C, Z Anal Chem., 1963, 196, 432-433.

6. $\quad$ Olatunji M A and Mc Auley A, J Chem Soc Dalton Trans., 1975, 682-688.

7. Zahid Amjad and Mc.Auley A, Inorg Chim Acta, 1977, 25, 127-130.

8. Olufunke Olagunju, Paul Siegel D, Rotimi Ologo and Simoyi R H, J Phys Chem A, 2006, 110(7), 2396-2410.

9. Simoyi R H, Irving R, Epstein and Kenneth Kustin, J Phys Chem., 1994, 98, 551-557.

10. Gyula Rabai and Mihaly T Beck, J Chem Soc Dalton Trans., 1985, 1669-1672.

11. Southard M Z, Green D W and Willhite G P, SPE/DOE, 1984, 12715.

12. Zaheer Khan, Mohammed Yousuf Dar, Prabijna SS Babu and Kabir-ud-Din, Indian J Chem., 2004, 42A, 1060-1065. 
13. Arifoglu M A, Marmer W N and Dudley R B, Textile Res., 1992, 62, 94-100.

14. Cagarra J, Gacen J, Caro M and Pepio M, J Soc Dyers Colour., 1988, 104, 273-279.

15. Ayres J A, Decontamination of Nuclear Reactors and Equipment, Ronald press Co; New York, 1970, 177.

16. Balasubramanian K and Prathiba V, Indian J Chem., 1986, 25B, 326.

17. Gopalarao G and Viswanatham C R, Curr Sci., 1942, 11, 102.

18. Kalthoff I M and Belcher R, Volumetric Analysis Volume III, (Inter Science Publishers, Inc. New York 1957, 387.

19. Bunton C A and Savelli G, Adv Phys Org Chem., 1986, 22, 213.

20. Bunton C A and Wolfe B, J Am Chem Soc., 1973, 95, 3742.

21. Pramauro E, Pelizzetti E, Diekman S and Frahm J, Inorg Chem., 1982, 21, 2432-2436.

22. Kumar D and Balasubramanian K, J Col Inter Sci., 1979, 69(2), 271-279.

23. Lin H Y and Thomas J L, Langmuir, 2003, 19, 1098-1105.

24. Feigl F, Spot test in organic Analysis, Elsevier Publishing Company, New York, 1996, 290.

25. Preisler P W and Berger L, J Am Chem Soci., 1947, 69, 322-325. 